\title{
UMA PROPOSTA LINGUÍSTICA DE CLASSIFICAÇÃO DE CONSTITUINTES MORFOLÓGICOS QUE COMPÕEM FORMAS VERBAIS LATINAS
}

\section{A LINGUISTIC PROPOSAL FOR THE CLASSIFICATION OF MORPHOLIGICAL CONSTITUENTS THAT COMPOSE LATIN VERBAL FORMS}

\author{
Soraya Paiva Chain ${ }^{1}$ \\ Victor de Lima Serudo ${ }^{2}$ \\ Universidade Federal do Amazonas
}

\section{RESUMO}

Tomando como base a comutação que se faz no eixo paradigmático para a identificação e classificação de morfema (SAUSSURE, 2012, p. 171-175) e (CASTILHO, 2010, p. 46-48), inquietamo-nos quanto à classificação apresentada nas Gramáticas Latinas, a respeito de alguns constituintes (vogal de ligação, desinência modo-temporal e desinência número-pessoal), em determinadas conjugações. Por conta disso, apresentamos este estudo, no qual discutimos a classificação de alguns constituintes, com base na Teoria Estruturalista - que estuda a estrutura e a formação dos vocábulos, colocando o morfema no centro da análise -, para demonstrarmos todos os morfemas/elementos que constituem cada forma (pessoa/modo-tempo/conjugação) verbal latina da diátese ativa, nos tempos do infectum, e, com isso, apresentarmos uma proposta de classificação de alguns constituintes verbais latinos, condizente com estudos linguísticos modernos. PALAVRAS-CHAVE: Linguística; Língua Latina; Morfologia; Constituintes verbais.

\begin{abstract}
Based on the commutation that takes place on the paradigmatic axis for the identification and classification of morphemes (SAUSSURE, 2012, p. 171-175) and (CASTILHO, 2010, p. 46-48), we are concerned about the classification presented in Latin grammars, regarding some constituents (connecting vowel, mode-temporal ending and number-personal ending), in certain conjugations. Due to this, we present this study, in which we discuss the classification of some constituents, based on the Structuralist Theory - which studies the structure and formation of words, placing the morpheme at the center of analysis -, to demonstrate all the morphemes/elements that constitute each Latin verbal form (person/time-mode/conjugation) of the active diathesis, in the times of the infectum. With this, we present a proposal for the classification of some Latin verbal constituents, consistent with modern linguistic studies.
\end{abstract}

KEYWORDS: Linguistics; Latin; Morphology; Verbal constituents.

\section{INTRODUÇÃO}

Os verbos latinos são apresentados nas Gramáticas Latinas (GLs) em quatro conjugações e mais uma terceira conjugação mista, de acordo com o tema que apresentam. Ou seja, os verbos da primeira conjugação têm tema em $a$, os da segunda conjugação têm tema em $e$, os da terceira são atemáticos, significando dizer que têm tema em consoante, e os da terceira mista e da quarta conjugações têm tema em $i$.

\footnotetext{
${ }^{1}$ Doutora em Linguística pela Universidade Federal de Santa Catarina (UFSC). E-mail: sorayachain4@gmail.com.

${ }^{2}$ Graduando em Letras pela Universidade Federal do Amazonas (UFAM). E-mail: victorssserudo@gmail.com.
} 
As gramáticas latinas apresentam os verbos conjugados em todas as pessoas de todos os modos-tempos, tanto no singular quanto no plural, mostrando os constituintes morfológicos de cada forma/pessoa. Porém, algumas classificações morfológicas apresentadas pelas GLs - como, por exemplo, classificar uma vogal como vogal de ligação em ambiente que não justifica a presença desse tipo de constituinte - podem ser ajustadas de acordo com estudos linguísticos modernos.

Neste artigo, objetivamos discutir a classificação de alguns morfemas verbais latinos dos tempos do infectum ${ }^{3}$, para, com base na teoria estruturalista, que toma como centro de análise os morfemas, propormos uma nova classificação a alguns constituintes de algumas pessoas de determinados modos-tempos/conjugações verbais. Organizamos o texto em três seções: inicialmente, apresentamos a classificação dos constituintes de todas as pessoas de cada uma das conjugações verbais, nos tempos do infectum, de acordo com as gramáticas latinas (GLs); na segunda seção, apresentamos aspectos da morfologia estruturalista, que subsidiam nossas análises; na terceira seção, discutimos a respeito da classificação de alguns morfemas verbais latinos, para os quais apresentamos uma nova classificação.

\section{Verbos, nos tempos do infectum, com base em Gramáticas Latinas}

Tomaremos como base, para a descrição que apresentaremos das conjugações verbais, três obras de autores distintos: a Gramática Básica do Latim, de Oswaldo Furlan e Raulino Bussarello (1997); o Compêndio de Gramática Latina, de Maria Almendra e José Figueiredo (2003); e a Gramática Latina, de Antônio Freire (1987).

Cada um desses gramáticos apresenta quatro conjugações verbais latinas - e mais a terceira (mista) - utilizando um verbo representativo de cada uma delas. Como ilustração, observemos os seguintes verbos: abnego, as, àre, verbo da primeira conjugação (C1); fulgeo, es, ère, verbo da segunda conjugação (C2); lacesso, is, ère, verbo da terceira conjugação (C3); prosilio, is, ère, verbo da terceira conjugação mista (C3 (m)) e definio, is, ire, verbo da quarta conjugação (C4).

Como ponto de partida, apresentamos, no quadro abaixo, um paradigma verbal do presente do indicativo, tempo primitivo, do qual se derivam todos os outros tempos do infectum. $\mathrm{E}$ na sequência, vêm os outros tempos verbais. Para efeito de explicação, representaremos a configuração das formas verbais pelo esquema [R+VT+VL+DMT+DNP], cujos morfemas/constituintes correspondem, respectivamente, a: radical, vogal temática, vogal de ligação (como este constituinte tem a função de, como o nome já diz, ligar, ele pode, a depender do tempo, do modo e da pessoa verbal, aparecer em outra posição), desinência modo-temporal e desinência número-pessoal.

Nesses quadros, as siglas P1, P2 e P3 representam, respectivamente, as primeira, segunda e terceira pessoas do singular, e P4, P5 e P6, as primeira, segunda e terceira pessoas do plural.

Quadro 1: Paradigma conjugacional do Presente do Indicativo

\begin{tabular}{|c|l|l|l|l|l|}
\hline Conjugação & \multicolumn{1}{|c|}{ C1 } & \multicolumn{1}{|c|}{ C2 } & C3 & C3 (m) & \multicolumn{1}{c|}{ C4 } \\
\hline Tradução & Negar & Brilhar & Provocar & Saltar & Definir \\
\hline P1 & ABNEG-O & FULG-E-O & LACESS-O & PROSIL-I-O & DEFIN-I-O \\
\hline P2 & ABNEG-A-S & FULG-E-S & LACESS-I-S & PROSIL-I-S & DEFIN-I-S \\
\hline P3 & ABNEG-A-T & FULG-E-T & LACESS-I-T & PROSIL-I-T & DEFIN-I-T \\
\hline
\end{tabular}

\footnotetext{
3 São os tempos derivados do tema do presente do indicativo. Tempos de ação inacabada (ALMENDRA \& FIGUEIREDO, 2003, p. 80).
} 


\begin{tabular}{|c|l|l|l|l|l|}
\hline P4 & ABNEG-A-MUS & FULG-E-MUS & LACESS-I-MUS & PROSIL-I-MUS & DEFIN-I-MUS \\
\hline P5 & ABNEG-A-TIS & FULG-E-TIS & LACESS-I-TIS & PROSIL-I-TIS & DEFIN-I-TIS \\
\hline P6 & ABNEG-A-NT & FULG-E-NT & LACESS-U-NT & PROSIL-I-U-NT & DEFIN-I-U-NT \\
\hline
\end{tabular}

Fonte: dados da pesquisa

A disposição/classificação dos constituintes ocorre, conforme o quadro acima, da seguinte forma, no indicativo-presente: $[\mathrm{R}+\mathrm{DNP}]$, para a $\mathrm{P} 1$, e $[\mathrm{R}+\mathrm{VT}+\mathrm{DNP}]$, para as demais pessoas de verbos da $\mathrm{C} 1$; $[\mathrm{R}+\mathrm{DNP}]$, para a $\mathrm{P} 1$ e $[\mathrm{R}+\mathrm{VL}+\mathrm{DNP}]$, para as demais pessoas de verbos de $\mathrm{C} 3$; e [R+VT+DNP], para todas as pessoas de verbos de C2, C3-m e C4, com exceção da P6, das C3 (m) e C4, que se constitui de [R+VT+VL+DNP] (classificação que iremos discutir).

É válido observarmos que o indicativo-presente, por ser o tempo primitivo dos tempos do infectum, não apresenta o morfe de modo-tempo. Conforme Chain (2018, p. 213), esta falta de morfe configura "uma ausência significativa (logo, morfema zero [...] Ø), ou seja, falta de morfe (marca/desinência)", porém, presença de morfema (significado), que indica o modo e o tempo verbal. Passemos à descrição do paradigma do pretérito imperfeito do indicativo, futuro do presente, presente do subjuntivo, pretérito imperfeito do subjuntivo e presente do imperativo, nos quadros de 2 a 6 , abaixo relacionados:

Quadro 2: Paradigma conjugacional do Pretérito Imperfeito do Indicativo

\begin{tabular}{|c|l|l|c|l|l|}
\hline Conjugação & \multicolumn{1}{|c|}{ C1 } & \multicolumn{1}{|c|}{ C2 } & \multicolumn{1}{c|}{ C3 } & \multicolumn{1}{c|}{ C3 (m) } & \multicolumn{1}{c|}{ C4 } \\
\hline Tradução & Negar & \multicolumn{1}{|c|}{ Brilhar } & Provocar & Definir \\
\hline P1 & ABNEG-A-BA-M & FULG-E-BA-M & LACESS-E-BA-M & PROSIL-I-E-BA-M & DEFIN-I-E-BA-M \\
\hline P2 & ABNEG-A-BA-S & FULG-E-BA-S & LACESS-E-BA-S & PROSIL-I-E-BA-S & DEFIN-I-E-BA-S \\
\hline P3 & ABNEG-A-BA-T & FULG-E-BA-T & LACESS-E-BA-T & PROSIL-I-E-BA-T & DEFIN-I-E-BA-T \\
\hline P4 & ABNEG-A-BA-MUS & FULG-E-BA-MUS & LACESS-E-BA-MUS & PROSIL-I-E-BA-MUS & DEFIN-I-E-BA-MUS \\
\hline P5 & ABNEG-A-BA-TIS & FULG-E-BA-TIS & LACESS-E-BA-TIS & PROSIL-I-E-BA-TIS & DEFIN-I-E-BA-TIS \\
\hline P6 & ABNEG-A-BA-NT & FULG-E-BA-NT & LACESS-E-BA-NT & PROSIL-I-E-BA-NT & DEFIN-I-E-BA-NT \\
\hline
\end{tabular}

Fonte: dados da pesquisa

No quadro 2, os constituintes morfológicos do indicativo-pretérito imperfeito são dispostos/classificados assim: $[\mathrm{R}+\mathrm{VT}+\mathrm{DMT}+\mathrm{DNP}]$, para todas as pessoas dos verbos das $\mathrm{C} 1 \mathrm{e}$ $\mathrm{C} 2 ;[\mathrm{R}+\mathrm{VL}+\mathrm{DMT}+\mathrm{DNP}]$, para todas as pessoas de verbos da $\mathrm{C} 3$; e $[\mathrm{R}+\mathrm{VT}+\mathrm{VL}+\mathrm{DMT}+\mathrm{DNP}]$, para todas as pessoas de verbos das C3 (m) e C4 (outra classificação que iremos discutir).

Quadro 3: Paradigma conjugacional do Futuro do Presente do Indicativo

\begin{tabular}{|c|c|c|c|c|c|}
\hline Conjugação & C1 & C2 & C3 & C3 (m) & C4 \\
\hline Tradução & Negar & Brilhar & Provocar & Saltar & Definir \\
\hline P1 & ABNEG-A-B-O & FULG-E-B-O & LACESS-A-M & PROSIL-I-A-M & DEFIN-I-A-M \\
\hline P2 & ABNEG-A-B-I-S & FULG-E-B-I-S & LACESS-E-S & PROSIL-I-E-S & DEFIN-I-E-S \\
\hline
\end{tabular}




\begin{tabular}{|c|l|l|l|l|l|}
\hline P3 & ABNEG-A-B-I-T & FULG-E-B-I-T & LACESS-E-T & PROSIL-I-E-T & DEFIN-I-E-T \\
\hline P4 & ABNEG-A-B-I-MUS & FULG-E-B-I-MUS & LACESS-E-MUS & PROSIL-I-E-MUS & DEFIN-I-E-MUS \\
\hline P5 & ABNEG-A-B-I-TIS & FULG-E-B-I-TIS & LACESS-E-TIS & PROSIL-I-E-TIS & DEFIN-I-E-TIS \\
\hline P6 & ABNEG-A-B-U-NT & FULG-E-B-U-NT & LACESS-E-NT & PROSIL-I-E-NT & DEFIN-I-E-NT \\
\hline
\end{tabular}

Fonte: dados da pesquisa

No quadro 3, os constituintes morfológicos do indicativo-futuro do presente são dispostos/classificados da seguinte forma: $[\mathrm{R}+\mathrm{VT}+\mathrm{DMT}+\mathrm{DNP}]$, para a P1, e $[\mathrm{R}+\mathrm{VT}+\mathrm{DMT}+\mathrm{VL}+\mathrm{DNP}]$, para as demais pessoas de verbos das $\mathrm{C} 1 \mathrm{e} \mathrm{C} 2$; [R+DMT+DNP], para todas as pessoas dos verbos da C3; e [R+VT+DMT+DNP], para todas as pessoas dos verbos das C3 (m) C4.

\begin{tabular}{|c|l|l|l|l|l|}
\hline \multicolumn{7}{|c|}{ Quadro 4: Paradigma conjugacional do Presente do Subjuntivo } \\
\hline Conjugação & \multicolumn{1}{|c|}{ C1 } & \multicolumn{1}{|c|}{ C2 } & C3 & C3 (m) & \multicolumn{1}{c|}{ C4 } \\
\hline Tradução & Negar & Brilhar & Provocar & Saltar & Definir \\
\hline P1 & ABNEG-E-M & FULG-E-A-M & LACESS-A-M & PROSIL-I-A-M & DEFIN-I-A-M \\
\hline P2 & ABNEG-E-S & FULG-E-A-S & LACESS-A-S & PROSIL-I-A-S & DEFIN-I-A-S \\
\hline P3 & ABNEG-E-T & FULG-E-A-T & LACESS-A-T & PROSIL-I-A-T & DEFIN-I-A-T \\
\hline P4 & ABNEG-E-MUS & FULG-E-A-MUS & LACESS-A-MUS & PROSIL-I-A-MUS & DEFIN-I-A-MUS \\
\hline P5 & ABNEG-E-TIS & FULG-E-A-TIS & LACESS-A-TIS & PROSIL-I-A-TIS & DEFIN-I-A-TIS \\
\hline P6 & ABNEG-E-NT & FULG-E-A-NT & LACESS-A-NT & PROSIL-I-A-NT & DEFIN-I-A-NT \\
\hline
\end{tabular}

Fonte: dados da pesquisa

No quadro 4, os constituintes morfológicos do subjuntivo-presente são dispostos/classificados desta forma: $[\mathrm{R}+\mathrm{DMT}+\mathrm{DNP}]$, para todas as pessoas dos verbos da C1; $[\mathrm{R}+\mathrm{VT}+\mathrm{DMT}+\mathrm{DNP}]$, para todas as pessoas de verbos da $\mathrm{C} 2 ; \mathrm{R}+\mathrm{DMT}+\mathrm{DNP}]$, para todas as pessoas dos verbos da C3; [R+VT+DMT+DNP], para todas as pessoas de verbos das C3 (m) e C4.

Quadro 5: Paradigma conjugacional do Pretérito Imperfeito do Subjuntivo

\begin{tabular}{|c|c|l|l|l|l|}
\hline Conjugação & C1 & C2 & C3 & C3 (m) \\
\hline Tradução & Negar & Brilhar & Provocar & Saltar \\
\hline P1 & ABNEG-A-RE-M & FULG-E-RE-M & LACESS-E-RE-M & PROSIL-E-RE-M & DEFinir \\
\hline P2 & ABNEG-A-RE-S & FULG-E-RE-S & LACESS-E-RE-S & PROSIL-E-RE-S & DEFIN-I-RE-S \\
\hline P3 & ABNEG-A-RE-T & FULG-E-RE-T & LACESS-E-RE-T & PROSIL-E-RE-T & DEFIN-I-RE-T \\
\hline P4 & ABNEG-A-RE-MUS & FULG-E-RE-MUS & LACESS-E-RE-MUS & PROSIL-E-RE-MUS & DEFIN-I-RE-MUS \\
\hline P5 & ABNEG-A-RE-TIS & FULG-E-RE-TIS & LACESS-E-RE-TIS & PROSIL-E-RE-TIS & DEFIN-I-RE-TIS \\
\hline
\end{tabular}




\begin{tabular}{|c|l|l|l|l|l|}
\hline P6 & ABNEG-A-RE-NT & FULG-E-RE-NT & LACESS-E-RE-NT & PROSIL-E-RE-NT & DEFIN-I-RE-NT \\
\hline
\end{tabular}

Fonte: dados da pesquisa

No quadro 5, os constituintes morfológicos do subjuntivo-pretérito imperfeito são dispostos/classificados assim: [R+VT+DMT+DNP], para todas as pessoas dos verbos das C1, C2, $\mathrm{C} 3(\mathrm{~m})$ e $\mathrm{C} 4$; e $[\mathrm{R}+\mathrm{VL}+\mathrm{DMT}+\mathrm{DNP}]$, para todas as pessoas dos verbos da C3.

Quadro 6: Paradigma conjugacional do Presente do Imperativo

\begin{tabular}{|c|c|c|c|c|c|}
\hline Quadro 6: Paradigma conjugacional do Presente do Imperativo \\
\hline Conjugação & C1 & C2 & C3 & C3 (m) & C4 \\
\hline Tradução & Negar & Brilhar & Provocar & Saltar & Definir \\
\hline P2 & ABNEG-A & FULG-E & LACESS-E & PROSIL-E & DEFIN-I \\
\hline P5 & ABNEG-A-TE & FULG-E-TE & LACESS-I-TE & PROSIL-I-TE & DEFIN-I-TE \\
\hline
\end{tabular}

Fonte: dados da pesquisa

No quadro 6, os constituintes morfológicos do imperativo-presente (que apresenta somente as segundas pessoas - P2 e P5) são dispostos/classificados da seguinte forma: [R+VT], para a P2, e $[\mathrm{R}+\mathrm{VT}+\mathrm{DNP}]$, para a $\mathrm{P} 5$ dos verbos das $\mathrm{C} 1, \mathrm{C} 2, \mathrm{C} 3(\mathrm{~m})$ e $\mathrm{C} 4$; $[\mathrm{R}+\mathrm{VL}]$, para a P2 (classificação que iremos explicar), e [R+VL+DNP], para a P5 de verbos da C3.

Tendo apresentado, conforme as GLs, o paradigma conjugacional de todas as conjugações nos tempos do infectum, passemos ao estudo dos constituintes morfológicos do verbo, à luz da teoria estruturalista, para, em seguida, apresentarmos uma discussão linguística acerca da classificação de alguns morfemas verbais latinos.

\section{Estudo sobre aspectos da morfologia do verbo sob a visão estruturalista}

O Estruturalismo é uma teoria linguística que analisa as estruturas linguísticas em diferentes níveis: fonológico, morfológico e sintático. Essa concepção entende a língua como um fenômeno complexo, organizado por partes, para constituir um todo estruturável (CASTILHO, 2014, p. 673). Sabendo que a língua é estruturada em níveis, de forma sistematizada, e que cada nível de análise requer uma organização específica, pode o analista da língua realizar análises em um nível específico ou em dois ou mais, caso sua investigação necessite.

Os estudos estruturalistas têm como base os princípios postulados pelo suíço Ferdinand de Saussure, que partiu do pressuposto de que, dentro de um sistema, os elementos são definidos por relações e diferenças entre os constituintes. Conforme apresenta Saussure (2012, p. 171), "as relações e as diferenças entre termos linguísticos se desenvolvem em duas esferas distintas, cada uma das quais é geradora de certa ordem de valores; a oposição entre essas duas ordens faz compreender melhor a natureza de cada uma".

As duas esferas de que o linguista fala são o eixo sintagmático (horizontal) - no qual os constituintes se relacionam - e o eixo paradigmático (vertical) - no qual os constituintes se diferenciam. Quando focamos em um constituinte de uma estrutura, podemos observar as relações de sentido que ele mantém com os outros constituintes anteriores e posteriores a ele - relações sintagmáticas. Focando no mesmo termo, podemos substituí-lo por outro equivalente, para observarmos a diferença de sentido - relação paradigmática.

Sintagma versus paradigma é uma das dicotomias saussurianas. Sobre sintagma, Saussure (2012, p. 171) aduz que

[...] no discurso, os termos estabelecem entre si, em virtude de seu encadeamento, relações baseadas no caráter linear da língua, que exclui a possibilidade de pronunciar 
dois elementos ao mesmo tempo [...]. Estes se alinham um após o outro na cadeia da fala. Tais combinações, que se apoiam na extensão, podem ser chamadas de sintagmas. [...] Colocado num sintagma, um termo só adquire seu valor porque se opõe ao que o precede ou ao que o segue, ou a ambos.

Relacionando esses aspectos à morfologia do verbo, observamos que os constituintes de uma forma verbal se combinam linearmente, estando assim organizados $[\mathrm{R}+\mathrm{V} T+\mathrm{VL}+\mathrm{DMT}+\mathrm{DNP}]$. Desse modo, cada elemento na sua relação com o antecede e/ou com o item que o segue, adquire valor - um em oposição ao outro -, sem apresentar outro constituinte de mesma natureza. Logo não se terá duas vogais temáticas ou duas desinências número-pessoais etc.

Já, a respeito de paradigma, ou relações paradigmáticas ${ }^{4}$, Saussure (2012, p. 172) diz que "fora do discurso, as palavras que oferecem algo de comum se associam na memória e assim se formam grupos dentro dos quais imperam relações muito diversas". Esses "[...] grupos formados por associação mental não se limitam a aproximar os termos que apresentem algo em comum; o espírito capta também a natureza das relações que os unem em cada caso e cria com isso tantas séries associativas quantas relações diversas existam” (SAUSSURE, 2012, p. 174).

Nesse ínterim, podemos observar que, no caso dos constituintes verbais, há, por exemplo, o grupo das desinências número-pessoais, que são constituintes de mesma natureza, pois todas que fazem parte desse grupo têm sempre a função de demonstrar o número e a pessoa verbal, mesmo que sejam distintas entre si, pois cada uma representa especificamente um número e uma pessoa.

$\mathrm{Na}$ teoria estruturalista, os constituintes são analisados de forma isolada, dentro de um nível de análise (trabalhamos aqui com o nível morfológico), considerando os termos adjuntos. É com base nessa proposição que analisamos as estruturas verbais que demonstraremos mais à frente.

Apresentada uma noção inicial do que vem a ser Estruturalismo, além de retratarmos um pouco sobre sintagma e paradigma, relembremos morfema, ou seja, aquilo que entendemos como a menor unidade significativa e indivisível dentro de uma palavra. Um morfema é uma "unidade mínima da morfologia" (CASTILHO, 2014, p. 684), que possui um significado específico dentro de qualquer vocábulo.

Especificamente sobre a morfologia dos verbos, tema deste estudo, vale aqui falarmos um pouco dos constituintes que poderão aparecer nas formas que iremos analisar, como radical, vogal temática, vogal de ligação, desinência modo-temporal e desinência número-pessoal, além da noção de morfema zero.

O constituinte verbal que, conforme Kehdi (2007, p. 26) "corresponde ao elemento irredutível e comum às palavras de uma mesma família" é o radical. Dessa forma, compreendemos que o radical é uma parte comum e necessária dentro do verbo. Conforme observamos nos verbos latinos apresentados na seção anterior, por serem verbos regulares, seus radicais, conforme disposto nos quadros, não sofrem alterações dentro do paradigma verbal nos tempos do infectum: abneg-, fulg-, lacess-, prosil- e defin-.

Conforme observamos nas estruturas morfológicas dos verbos apresentados no tópico anterior, dentre os constituintes do verbo, há a vogal temática, que é o elemento que pode aparecer imediatamente após o radical do verbo para a construção de uma base, denominada tema. Essa vogal temática também estabelece a conexão de determinados morfemas ao radical, a depender do modo, tempo, conjugação e pessoa verbal.

No latim, as vogais temáticas são: $-a-$, para verbos da $\mathrm{C} 1$; $-e$-, para os verbos da $\mathrm{C} 2$; -i- ou o alomorfe $e^{5}-e$, para os verbos da C3 (m); e -i-, para verbos da C4. Os verbos da C3 são atemáticos, ou seja, nenhuma pessoa de nenhum modo-tempo é constituída com vogal temática.

\footnotetext{
${ }^{4}$ Saussure (2012) usa os termos associações (para paradigma) e relações associativas (para relações paradigmáticas).

${ }^{5}$ Cada uma das variantes que um morfema apresenta (BECHARA, p. 253, 2011).
} 
Também compõem a estrutura dos verbos as desinências modo-temporais e as desinências número-pessoais. Ambas são morfemas cujas utilizações são indispensáveis para o padrão da língua latina, já que carregam noções de modo/tempo e número/pessoa. No latim, as desinências modotemporais dos tempos do infectum são $b a, b, a, e, r e$, que correspondem, respectivamente, a: indicativo-imperfeito, indicativo-futuro do presente/subjuntivo-presente, indicativo-futuro do presente/subjuntivo-presente, subjuntivo-imperfeito), e as desinências número-pessoais são $\mathrm{o} / \mathrm{m}$, $s, t$, mus, tis, nt (respectivamente: P1, P2, P3, P4, P5 e P6), além de te para a P5 do imperativopresente (FURLAN \& BUSSARELLO, 1997, p. 57-78).

Fora as desinências número-pessoais (morfemas) representadas por morfes, conforme vimos acima, há também uma que não é representada por morfe, porém encerra morfema: a P2 do imperativo-presente. Tanto esta pessoa quanto os modos-tempos indicativo-presente (tempo primitivo) e imperativo-presente encerram morfema e devem ser representados por zero ( $)$ na análise morfológica. Entender morfema e morfe é imprescindível para entender morfema zero.

O morfema é uma abstração de um morfe, enquanto este é a realização daquele. Segundo Rosa (2019, p. 103), "o morfe é um segmento de enunciado, ou melhor, uma sequência fônica, a que é possível atribuir significado e que será posteriormente classificado num morfema. O morfema é, por conseguinte, uma abstração em relação ao morfe", que não precisa aparecer para encerrar morfema. E é justamente essa não existência de um morfe, ou seja, de uma forma relacionada à presença de um significado, que nos conduz à noção de morfema zero.

$\mathrm{Na}$ análise de formas verbais que apresentam ausência significativa - ausência de um morfe/forma, porém presença de significado - o morfema zero, representado pelo símbolo (Ø), representa a ausência. Como exemplo, podemos observar que, no quadro 1, todas as pessoas dos verbos conjugados no indicativo-presente não apresentam desinência modo-temporal. Essa ausência é significativa - pois se opõe à presença de uma, no eixo paradigmático, em outro modotempo -, sendo a desinência modo-temporal representada, em análises morfológicas, por um morfema zero $(\varnothing)$.

Todavia, conforme apresenta Kehdi (2007, p. 24, grifos do autor),

Só podemos postular um morfema $\varnothing$ se três condições forem satisfeitas: 1) é preciso que o morfema $\varnothing$ corresponda a um espaço vazio; 2 ) esse espaço vazio deve opor-se a um ou mais seguimentos (no par utilizado, o $\varnothing$ de falava contrapõe-se ao -mos de falávamos); 3) a noção expressa pelo morfema $\varnothing$ deve ser inerente à classe gramatical do vocábulo examinado. Em nosso exemplo, as noções de número e pessoa existem obrigatoriamente em qualquer forma verbal portuguesa.

Temos então que a ausência de desinência número-pessoal, no indicativo-presente (quadro 1), caracteriza-se como uma ausência significativa, pois se opõe a outro segmento dentro do eixo paradigmático, já que temos, no indicativo-imperfeito, ba como desinência modo-temporal. Além disso, a noção de tempo é inerente à língua latina para todas as formas verbais. Por isso, diante do que apresenta Kehdi (2007, p. 24), temos as condições necessárias para postularmos o morfema zero na análise morfológica em verbos conjugados no indicativo-presente.

Agora, vejamos um constituinte verbal que não é morfema, pois se trata de um morfe vazio que não carrega nenhuma significação (MONTEIRO, 2002, p. 49), mas que pode se fazer presente na estrutura verbal: a vogal de ligação. Segundo Chain (2018, p. 214), esse constituinte, fonema vocálico de ligação, aparece "entre dois morfemas com finalidade tanto de facilitar a pronúncia quanto de apresentar a palavra de acordo com o padrão silábico da língua". Ela, conforme pode ser observada nos quadros da seção anterior, pode aparecer nas formas verbais dos tempos do infectum, a depender da pessoa, modo-tempo e conjugação.

Entendendo o que é vogal de ligação e o que é morfe (forma) e morfema, entendemos que pode haver, nas formas verbais, morfe sem morfema, ou seja, apresentação de forma que não carrega significado, como é o caso da vogal de ligação, e que há morfema sem morfe, ou seja, 
inferência de significado sem apresentação de forma, como é o caso de todas as pessoas verbais, no indicativo-presente de todas as conjugações, que não apresentam desinência modo-temporal, mas que essa ausência significa que o verbo está em um modo-tempo específico (indicativopresente).

\section{Análise linguística acerca da classificação de alguns constituintes verbais latinos}

Antes de iniciarmos as análises de algumas formas verbais de tempos do infectum, para discutirmos acerca da classificação de alguns constituintes (vogal de ligação, desinência modotemporal e desinência número pessoal) de determinadas conjugações, faremos uma pequena abordagem sobre comutação - ferramenta imprescindível para identificação de morfemas no eixo paradigmático. Castilho afirma que "a comutação se baseia na oposição que se estabelece entre elementos presentes e elementos ausentes do corpus" (2014, p. 47, grifo do autor). Essa oposição de constituintes precisa ocorrer dentro de um mesmo paradigma, preservando, sempre, elementos significativos da estrutura, ou seja, dos outros paradigmas (CASTILHO, 2014, p. 47).

Nos exemplos abaixo, demonstramos: as relações no eixo sintagmático; as oposições no eixo paradigmático; bem como a comutação feita neste eixo. Em cada um dos exemplos apresentamos a segmentação dos constituintes da $\mathrm{P} 4$ do verbo de C2, fulgeo, es, ère, no indicativoimperfeito.

Exemplo 1

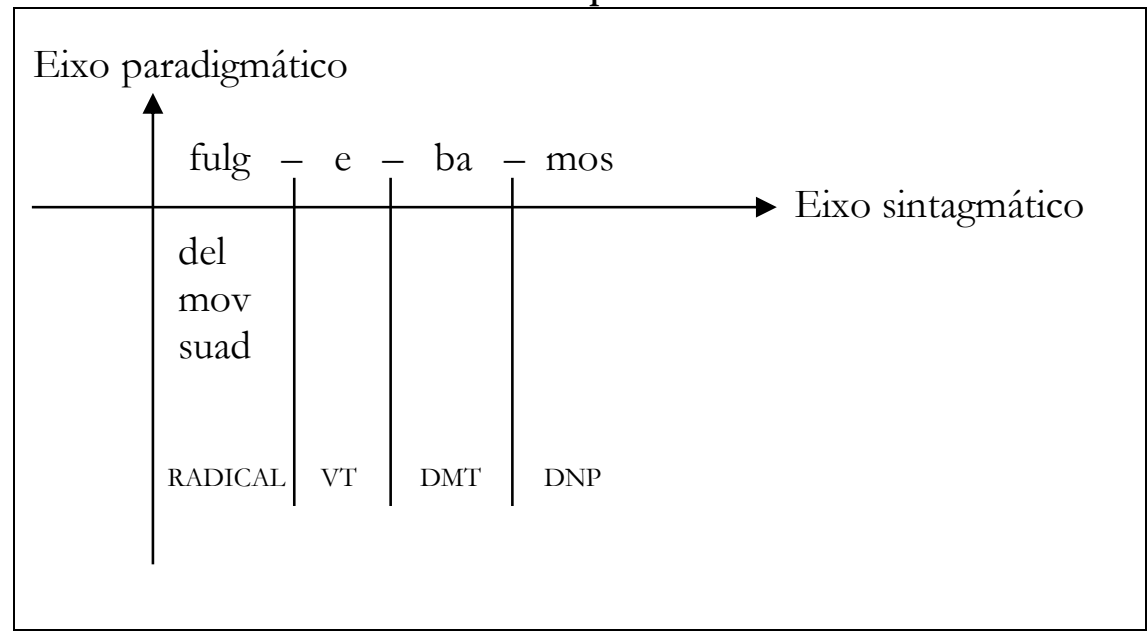

Fonte: dados da pesquisa

Exemplo 2

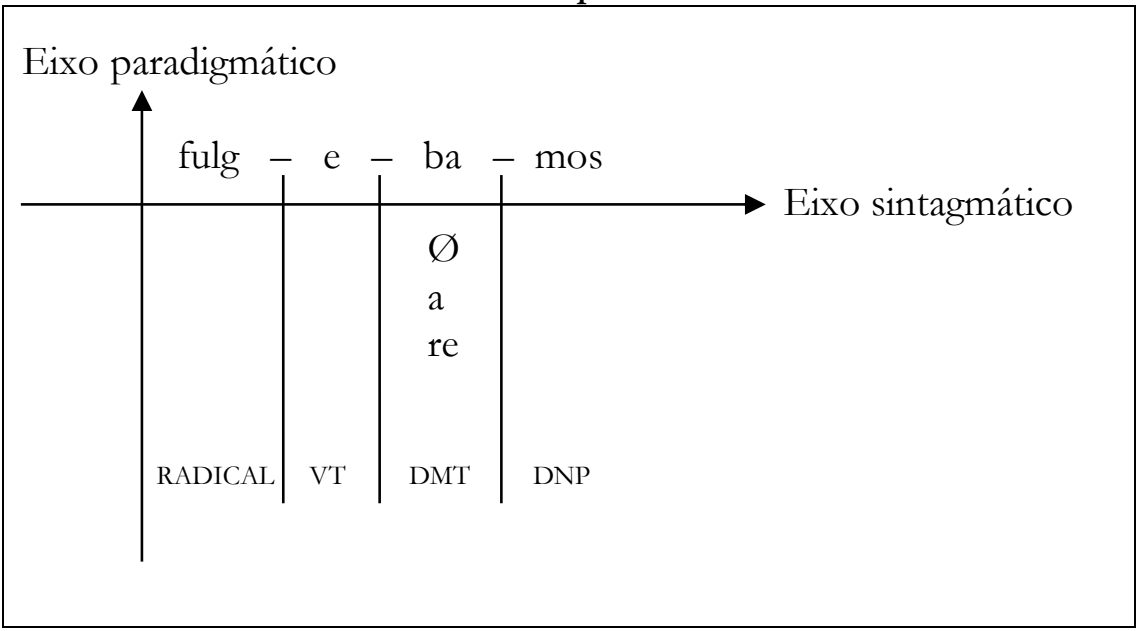

Fonte: dados da pesquisa 
Exemplo 3

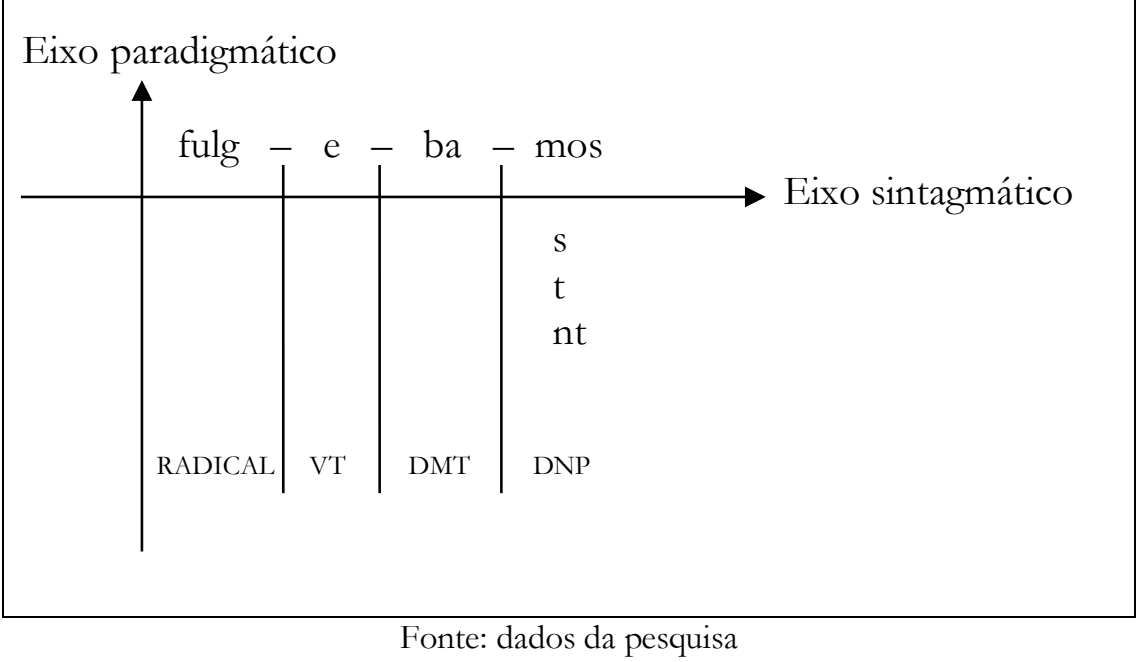

No exemplo 1, por meio da comutação (substituição de um elemento por outro em um mesmo paradigma, mantendo constantes os elementos dos outros paradigmas), apresentamos três possibilidades de radicais de outros verbos da mesma conjugação (respectivamente: deleo, es, ère; moveo, es, ère; suadeo, es, ère). No exemplo 2, alternamos três possibilidades de desinências modotemporais (respectivamente: indicativo presente; subjuntivo-presente; subjuntivo-imperfeito). E, no exemplo 3, apresentamos a comutação de três possibilidades de desinências número-pessoais (respectivamente: P2; P3; P6).

Partiremos agora à discussão dos constituintes verbais das C3, C3 (m) e C4, no indicativoimperfeito (quadro 2), no qual há a presença da vogal $e$, classificada pelas GLs como vogal de ligação nas C3, C3 (m) e C4, e da vogal $i$, classificada como vogal temática nas C3 (m) e C4.

Ao observarmos a disposição dos constituintes das conjugações verbais apresentados no quadro 2, em que temos o paradigma do radical, da vogal temática, ou da vogal de ligação (a depender da conjugação), da desinência modo-temporal e da desinência número-pessoal, observamos que a forma como os elementos são dispostos no paradigma segue uma ordenação, como, por exemplo, a DMT, que é a mesma em todas as pessoas de todas as conjugações. Tal ordenação se baseia em estudo gramatical, no qual se convém repetir as estruturas morfológicas dos constituintes verbais, tornando-os mais fáceis para a memorização, o que culminou em dizer gramaticalmente que $b a$ é a desinência modo-temporal para todas as pessoas.

Todavia, quando recorremos aos estudos linguísticos, por meio da comutação feita no eixo paradigmático, ficamos nos indagando a respeito da necessidade de uma vogal de ligação entre a vogal temática - que, por ser vogal já cumpre o papel de constituição de sílaba de acordo com o padrão silábico da língua latina - e a DMT nas pessoas das C3 (m) e C4.

Falando de padrão silábico, faz-se necessária uma fala acerca de sílaba, "unidade fonológica constituída por uma margem esquerda ou ataque silábico, um núcleo vocálico e uma margem direita ou coda. Nem todas as sílabas preenchem necessariamente todos esses constituintes, de que apenas o núcleo é obrigatório" (CASTILHO, 2014, p. 691). Grossomodo, o ataque silábico é a parte inicial da sílaba, ou seja, o(s) elemento(s) que aparece(m) antes do núcleo; o núcleo silábico, por sua vez, é constituído por uma vogal, sem a qual não há sílaba; e a coda silábica é a parte final da sílaba, a qual é formada pelo(s) elemento(s) que aparece $(\mathrm{m})$ depois do núcleo. A compreensão de como se forma uma sílaba é fundamental para entendermos a estrutura de um morfema, pois, na constituição de determinados vocábulos, a inserção de uma vogal de ligação se dá em função da necessidade de formamos uma sílaba que insira determinada palavra ao padrão silábico da língua.

Um bom exemplo de emprego de vogal de ligação (VL) exigido pelo padrão silábico da língua latina ocorre no indicativo-futuro do presente (quadro 3). $\mathrm{Na} \mathrm{P1}$, vemos que os verbos de 
C1 e C2 não possuem VL em suas estruturas. Isso se deve ao fato de que na P1, de ambas as conjugações, a DNP é constituída pela vogal $o$, que cumpre o papel de formadora de núcleo silábico, diferente das demais pessoas verbais, em que as DNPs são constituídas/iniciadas por consoante e a DMT, morfema anterior, é também constituída por consoante, impossibilitando formação de sílaba dentro dos moldes silábicos do latim. Nesse caso, a vogal de ligação ocorre para, além de dar apoio fônico, deixar as formas verbais de acordo com o padrão silábico da língua. Ou seja, como não há um contexto adequado para a formação de sílaba entre a DMT, constituída por uma consoante, e a DNP, também constituída/iniciada por consoante, nas P2, P3, P4, P5 e P6 deste modo-tempo, a VL aparece para deixar as formas verbais de acordo com o padrão silábico.

Diante disso, voltando ao indicativo-imperfeito (quadro 2), entendemos que as GLs classificam a vogal que aparece entre a vogal temática e a DMT, em todas as pessoas das C3 (m) e C4, como VL, para apresentar a DMT igual em todas as pessoas de todas as conjugações. Porém, podemos propor, à luz dos estudos linguísticos, uma releitura dessas estruturas verbais e considerar a vogal $e$ como parte da DMT para as C3 (m) e C4 neste modo-tempo, pois ela, apresentada como vogal de ligação pelas GLs nessas duas conjugações, é passível de releitura (reclassificação), já que ela não fora exigida, pelo padrão silábico da língua, para constituir núcleo silábico, uma vez que a vogal temática já cumpre este papel.

No quadro abaixo, mostramos a nova proposta de classificação para os constituintes das formas verbais das C3 (m) e C4 no indicativo-imperfeito.

Quadro 7: Pretérito Imperfeito do Indicativo: com nova classificação de constituintes

\begin{tabular}{|c|l|l|l|l|l|}
\hline Conjugação & \multicolumn{1}{|c|}{ C1 } & \multicolumn{1}{|c|}{ C2 } & C3 & \multicolumn{1}{c|}{ C3 (m) } & \multicolumn{1}{c|}{ C4 } \\
\hline Tradução & Negar & Brilhar & Provocar & Saltar & Definir \\
\hline P1 & ABNEG-A-BA-M & FULG-E-BA-M & LACESS-E-BA-M & PROSIL-I-EBA-M & DEFIN-I-EBA-M \\
\hline P2 & ABNEG-A-BA-S & FULG-E-BA-S & LACESS-E-BA-S & PROSIL-I-EBA-S & DEFIN-I-EBA-S \\
\hline P3 & ABNEG-A-BA-T & FULG-E-BA-T & LACESS-E-BA-T & PROSIL-I-EBA-T & DEFIN-I-EBA-T \\
\hline P4 & ABNEG-A-BA-MUS & FULG-E-BA-MUS & LACESS-E-BA-MUS & PROSIL-I-EBA-MUS & DEFIN-I-EBA-MUS \\
\hline P5 & ABNEG-A-BA-TIS & FULG-E-BA-TIS & LACESS-E-BA-TIS & PROSIL-I-EBA-TIS & DEFIN-I-EBA-TIS \\
\hline P6 & ABNEG-A-BA-NT & FULG-E-BA-NT & LACESS-E-BA-NT & PROSIL-I-EBA-NT & DEFIN-I-EBA-NT \\
\hline
\end{tabular}

Fonte: dados da pesquisa

A ordenação dos constituintes das C1, C2 e C3 permanece inalterada, ou seja, estão conforme o quadro 2. Já nas C3 (m) e C4, temos a reestruturação da DMT como eba, fazendo com que o paradigma verbal do indicativo-imperfeito encerre um padrão para todas as pessoas de todas as conjugações: $\mathrm{R}+\mathrm{VT} / \mathrm{VL}+\mathrm{DMT}+\mathrm{DNP}$.

Passemos agora à discussão acerca da incidência da vogal de ligação finalizando a P2 no imperativo-presente (quadro 6) de verbos da C3. Se a vogal de ligação, como o próprio nome já diz, apresenta-se para ligar constituintes verbais, como pode ela ser o último constituinte de uma forma verbal? Nesse caso, ela liga o radical, que é o termo que se apresenta antes dela, a que outro constituinte?

Para respondermos a estas perguntas, é necessário primeiro observarmos a formação desse modo-tempo, que se trata de um tempo derivado, formado a partir do radical do indicativopresente, tempo primitivo. Conforme aduz Faria (1958, p. 163, grifos do autor) "o Imperativo presente, que só tem as P2 e P5, é formado tomando-se para a P2 o tema puro do verbo, sem sufixo nem desinências pessoais, e para a P5, acrescentando-se ao tema do infectum a desinência te". 
O que o autor chama de sufixo é a DMT, ou seja, esse tempo, que é derivado, não apresenta DMT. Porém, sabemos que geralmente os tempos derivados se distinguem tanto do tempo primitivo (que não apresenta DMT por ser primitivo e, por isso, não precisa se distinguir de outrem, uma vez que veio primeiro) quanto dos outros derivados, através da DMT. Vemos que isso não ocorre com o imperativo-presente que, igualmente ao primitivo (indicativo-presente), não apresenta um morfe que informe o modo e o tempo verbal. Ele se diferencia do primitivo através da desinência (ou da falta de um morfe) número pessoal. Enquanto a P2 do primitivo apresenta $\operatorname{DNP} s$, a P2 deste derivado não apresenta morfe de número-pessoa, porém apresenta morfema, pois sua ausência é significativa, sendo então representada pelo morfema zero $\varnothing$ na análise morfológica. Já a P5 do primitivo apresenta DNP tis, enquanto que a P5 deste derivado é representada pela DNP te.

Após essas observações, em relação à formação e à composição do imperativo-presente, podemos entender o porquê de as formas verbais da P2 da C3, neste tempo, finalizarem na vogal de ligação, a qual, aparentemente, não liga o radical a nenhum outro elemento. Além de atentarmos para o fato de que a C3 é atemática - sendo isso o que gera a ocorrência da vogal de ligação logo após o radical, uma vez que, como já vimos acima, esse tempo não apresenta DMT, apesar de ser derivado - também precisamos atentar para a presença de morfema de número-pessoa - mesmo que este morfema não seja representado por um morfe - que, como já dissemos, é representado como morfema $\varnothing$ na análise morfológica.

Vamos agora discutir a respeito da vogal $u$ que aparece na P6 do indicativo-presente de verbos das C3 (m) e C4. Conforme fora apresentado no quadro 1, os verbos das C1, C2 e C3 possuem radical, vogal temática (com exceção da $\mathrm{P} 1$ dos verbos de $\mathrm{C} 1$ ), ou vogal de ligação - para a C3, que é atemática, (com exceção da P1) - e desinência número-pessoal. Já os verbos das C3 (m) e C4, após a vogal temática $i$, na P6, apresentam ainda, conforme a classificação apresentada pelas GLs, a vogal de ligação $u$. Nessas duas conjugações, o que as GLs apresentam como VL na P6 desse modo-tempo, nós, com base em análises linguísticas, entendemos como parte da DNP.

No quadro abaixo, mostramos a nova proposta de classificação dos constituintes da P6 no indicativo-presente de verbos das C3 (m) e C4.

Quadro 8: Presente do Indicativo: com nova classificação de constituintes

\begin{tabular}{|c|c|c|c|c|c|}
\hline Conjugação & C1 & C2 & C3 & C3 (m) & C4 \\
\hline Tradução & Negar & Brilhar & Provocar & Saltar & Definir \\
\hline P6 & ABNEG-A-NT & FULG-E-NT & LACESS-U-NT & PROSIL-I-UNT & DEFIN-I-UNT \\
\hline
\end{tabular}

Fonte: dados da pesquisa

No quadro acima, a P6 das C1, C2 e C3 estão da mesma forma que foram apresentadas no quadro 1. Nossa discussão aqui, como já apontamos acima, é a respeito da classificação da vogal $u$, que aparece na P6 das C3 (m) e C4. De acordo com observações que fizemos no eixo paradigmático de todas as conjugações desse modo-tempo, inferimos que o fato de a P6 da C3 apresentar uma vogal $u$ e esta ser classificada como VL, por conta de a C3 ser atemática, fez com que as GLs apresentassem a vogal $u$, que aparece na P6 das C3 (m) e C4, também como VL, como forma de convencionar um modelo estrutural facilitador de memorização.

No entanto, aqui também nos indagamos a respeito da necessidade de uma vogal de ligação entre a vogal temática - que, por ser vogal já cumpre o papel de constituição de sílaba de acordo com o padrão silábico da língua latina - e a DNP na P6 das C3 (m) e C4. Então, com base na comutação feita no eixo paradigmático para identificação e classificação de morfemas, entendemos que a DNP da P6 das C3 (m) e C4 no indicativo-presente é unt, conforme a nova classificação disposta no quadro acima. 
Com essa nova proposta de classificação dos constituintes da P6 nessas duas conjugações, o paradigma verbal do indicativo-presente encerra padrão estrutural R+VT/VL +DNP para todas as pessoas de todas as conjugações, com exceção apenas para a P1 das C1 e C3 que se estruturam somente com $\mathrm{R}+\mathrm{DNP}$.

Feita a descrição e análise dos paradigmas verbais nas diferentes conjugações e considerando estudos linguísticos atuais acerca de aspectos morfológicos, podemos ponderar os seguintes pontos:

I. A vogal apresentada pelas GLs como VL, no indicativo-imperfeito, é, na verdade, parte da DMT de verbos das C3 (m) e C4. Tem-se, então, eba como DMT para todas as pessoas de verbos dessas duas conjugações nesse modo-tempo. Com essa leitura/classificação, baseada em estudos linguísticos modernos, encerra-se um padrão estrutural para todas as pessoas de todas as conjugações no indicativo-imperfeito, $\mathrm{R}+\mathrm{VT} / \mathrm{VL}+\mathrm{DMT}+\mathrm{DNP}$, (quadro 7), o que não acontece com a leitura/classificação gramatical (quadro 2);

II. A partir da compreensão da formação do imperativo-presente, observamos que a presença da vogal de ligação, finalizando a P2 (em que não vemos o morfema posterior ligado por ela) de verbos da C3, exercerá a função de ligar o radical ao morfema zero, representado por $\varnothing$ na análise morfológica, conforme discussão apresentada;

III. Com base nas análises feitas nos eixos paradigmáticos, entendemos que a vogal da P6 dos verbos das C3 (m) e C4 no tempo indicativo-presente, classificada como VL pelas GLs, é, na verdade, parte da DNP, já que o ambiente não necessita de VL, pois há a VT para constituição da sílaba. Com essa leitura/classificação, encerra-se um padrão estrutural para as pessoas de todas as conjugações no indicativo-presente, $\mathrm{R}+\mathrm{VT} / \mathrm{VL}+\mathrm{DNP}$, com exceção apenas para a P1 das C1 e C3 que se estruturam somente com R+DNP (quadro 8), que difere da leitura/classificação gramatical (quadro 1).

\section{CONSIDERAÇÕES FINAIS}

Nesta pesquisa, apresentamos algumas discussões linguísticas - fundamentadas em aspectos estruturalistas, como a comutação -, para propor uma nova classificação a alguns constituintes morfológicos que compõem formas verbais latinas nos tempos do infectum, pois observamos que a forma como as GLs apresentam a classificação de alguns constituintes verbais não é condizente com estudos linguísticos modernos.

Ressaltamos que, mesmo tendo seguido, em nossa pesquisa, o modelo gramatical de apresentação dos verbos latinos, queremos apresentar aqui uma leitura linguística acerca dos verbos, demonstrados pelas GLs como verbos de C3 (m). Apesar dessa apresentação gramatical, sabemos que há, em latim, somente quatro conjugações verbais (C1, C2, C3 e C4). Sendo assim, entendemos que a C3 (m) - como alguns constituintes verbais que apontamos acima - é uma forma convencionada pelas GLs, que constroem um modelo conjugacional a mais para facilitar a memorização.

Não é à toa que esses verbos são denominados gramaticalmente como de C3 (m) e são colocados entre a C3 e a C4, pois são verbos cuja forma, em alguns tempos, mostra-se tal qual um verbo da C3, porém seus constituintes são classificados como os constituintes de verbos da C4.

Diante disso, podemos entender que esses verbos são, na verdade, verbos de C4, bastando apenas lê-los de acordo com estudos linguísticos modernos, considerando a alomorfia ${ }^{6}$ da VT, que se apresenta em algumas formas de alguns tempos verbais, conforme demonstramos no quadro abaixo.

Quadro 9: Para entender que os verbos de C3 (m) são, na verdade, de C4

\footnotetext{
${ }^{6}$ Alomorfes são diferentes formas (morfes) que um morfema assume em função do contexto linguístico. Variantes que representam um mesmo morfema (LAROCA, 2003, p. 29).
} 


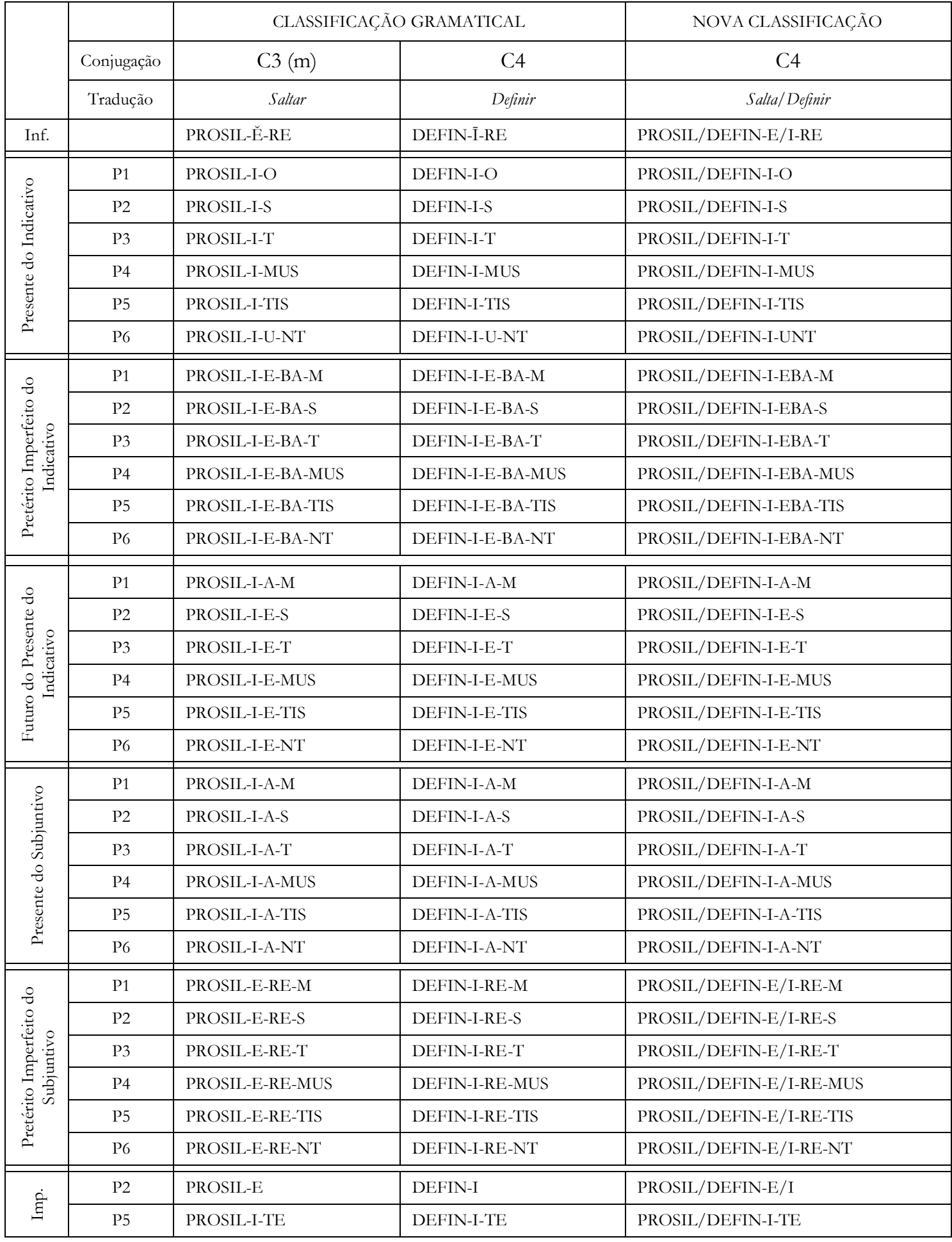

Fonte: dados da pesquisa

Vale relembrarmos aqui que a $\mathrm{C} 1$ tem tema em $a$, a C2 tem tema em $e$, a C3 é atemática e a $\mathrm{C} 4$ tem tema em $i$. Diante dessa e das demais ponderações que apresentamos com base na comutação é que dizemos que os verbos classificados por alguns gramáticos como sendo de C3 (m) são, na verdade, da C4, pois também têm tema em $i$. Porém, em alguns tempos, essa VT se apresenta como $e$, alomorfe de $i$.

Sendo assim, de acordo com o quadro acima, podemos perceber a alomorfia da VT já na forma de infinitivo, onde o ě de prosilěre (verbo classificado gramaticalmente como de C3 (m)) 
encerra a VT, alomorfe de $i$ (VT da C4). Essa primeira observação precisa ser considerada para identificarmos que: um verbo de C4 terá VT $e$ (alomorfe) em todas as pessoas do subjuntivoimperfeito e na P2 do imperativo, quando ele tiver essa mesma VT já no infinitivo, como prosilère (no dicionário: prosilio, is, ère); e um verbo de C4 terá VT $i$ em todas as pessoas do subjuntivoimperfeito e na P2 do imperativo, quando ele tiver essa mesma VT já no infinitivo, como definire (no dicionário: definio, is, îre).

Por fim, entendemos que, mesmo que tenhamos apresentado dados importantes e hesitações cientificamente demonstradas, nossa investigação, ainda inicial, acerca da classificação dos verbos, demonstrados como de C3 (m) pelas GLs, pode render questionamentos.

\section{REFERÊNCIAS}

ALMENDRA, Ana Maria; FIGUEIREDO, José Nunes de. Compêndio de gramática latina. Portugal: Porto Editora, 2003.

BECHARA, Evanildo. Dicionário da Lingua Portuguesa. - 1. Ed. - Rio de Janeiro : Editora Nova Fronteira, 2011.

CASTILHO, Ataliba T. de. Nova gramática do português brasileiro. $1^{a}$ ed. $3^{a}$ reimpressão. São Paulo: Contexto, 2014.

CHAIN, Soraya Paiva. Uma proposta de classificação dos constituintes morfologicos que compõem os substantivos latinos. Revista DLCV - Língua, Linguística \& Literatura. UFPB (João Pessoa), v. 14, n. 2, p. 207 230, 2018.

FARIA, Ernesto. Fonética Histórica do Latim. Rio de Janeiro, Livraria Acadêmica, 1958.

FREIRE, Antônio. Gramática latina. 5a ed. Braga: Livraria Apostolado da Imprensa, 1987.

FURLAN, Oswaldo A; BUSSARELLO, Raulino. Gramática básica do latim. $3^{a}$ ed. Florianópolis: Ed. da UFSC, 1997.

KEHDI, Valter. Morfemas do Português. $7^{\mathrm{a}}$ ed. São Paulo: Ática, 2007.

LAROCA, Maria Nazaré de. (2003). Manual de morfologia do português. 3 ed. Campinas: Pontes; Juiz de Fora, MG: UFJF, 2003.

MONTEIRO, José Lemos. Morfologia Portuguesa. $4^{\mathrm{a}}$ ed. Campinas: Pontes, 2002.

ROSA, Maria Carlota. Introdução à morfologia. São Paulo: Contexto, 2019.

SAUSSURE, Ferdinando de. Curso de linguística geral. 30ª ed. São Paulo: Cultrix, 2012.

Submetido em 04/09/2020

Aceito em 17/11/2020 